\title{
Early Stage of Solid State Interfacial Reaction between Copper and Tin
}

\author{
Masakatsu Maeda ${ }^{1, a}$, Naoto Inoue ${ }^{1}$, Takaaki Sato ${ }^{1}$, Yasuo Takahashi ${ }^{1, b}$ \\ 'Osaka University, 2-1 Yamadaoka, Suita, Osaka 565-0871, Japan \\ amaeda@casi.osaka-u.ac.jp, btakasy@casi.osaka-u.ac.jp
}

Keywords: copper, tin, interfacial structure, solid-state reaction, incubation time.

\begin{abstract}
High-purity plates of $\mathrm{Cu}$ and $\mathrm{Sn}$ were diffusion bonded to clarify the early stage of the solid state interfacial reaction between $\mathrm{Cu}$ and $\mathrm{Sn}$, focusing on the incubation time for the formation of intermetallic compounds. A clear incubation time for the formation of intermetallic compounds is observed at every temperature between 423 and $493 \mathrm{~K}$. The incubation time changes depending on the annealing temperature. The interface annealed at $423 \mathrm{~K}$ for $3.60 \mathrm{ks}$ maintains the direct interconnection between $\mathrm{Cu}$ and $\mathrm{Sn}$ being free of intermetallic compounds. The exposure of $\mathrm{Cu}$ surface to air affects the interfacial reaction. Annealing of the $\mathrm{Cu} / \mathrm{Sn}$ interface at $493 \mathrm{~K}$ for $3600 \mathrm{~s}$ starts to form voids by using the $\mathrm{Cu}$ plates exposed for $8.64 \times 10^{4} \mathrm{~s}$ or longer to air. Furthermore, the reaction product layer formed by the same annealing condition becomes thinner when the $\mathrm{Cu}$ plates exposed for $8.64 \times 10^{5} \mathrm{~s}$ or longer to air are used.
\end{abstract}

\section{Introduction}

The interfacial reaction behavior between $\mathrm{Cu}$ and $\mathrm{Sn}$ has been investigated by numerous researchers for a long time [1-8]. Recently, the behavior has become more important than ever in electrical and electronic industrial fields as the phenomenon dominating the performance and the reliability of the interface between $\mathrm{Cu}$ lead-frames and Sn-based lead-free solders. A number of reports suggest that the formation of intermetallic compounds at the interface leads to severe deterioration in the interfacial strength and the electrical conductivity [6]. Therefore, a technology is demanded to form the direct interconnection between $\mathrm{Cu}$ and $\mathrm{Sn}$ free of intermetallic compounds and to maintain the interface. Although the growth behavior of the intermetallic compounds during long term annealing has been investigated in detail, the early stage of the interfacial reaction has not been clearly understood. The knowledge on the interfacial behavior in the early stage of annealing is important for preventing the formation of intermetallic compounds.

The present study has been carried out to clarify the interfacial reaction behavior between $\mathrm{Cu}$ and $\mathrm{Sn}$ in the early stage of annealing at temperatures below the lowest eutectic in the Cu-Sn binary system [9], focusing on the incubation time for the formation of intermetallic compounds. The effect of the exposure time of $\mathrm{Cu}$ and $\mathrm{Sn}$ surfaces to air, which will be accounted for the formation of oxide films on the surfaces, is also investigated.

\section{Incubation Time for Formation of Interfacial Reaction Products}

The formation and growth behavior of the intermetallic compound $\mathrm{A}_{\mathrm{a}} \mathrm{B}_{\mathrm{b}}$ at a flat interface of a A-B binary diffusion pair is considered assuming uniform one-dimensional interdiffusion of the constituent atoms across the interface. The $x$-axis is settled perpendicular to the interface which positioned at $x_{0}$. The diffusion flux $J_{i j}$ of the element $i$ in the phase $j$ existing at the position $x$ is expressed using the Fick's first law as:

$$
J_{i j}(x)=-D_{i j} \frac{\partial C_{i}}{\partial x} ; i=\mathrm{A} \text { or } \mathrm{B} ; j=(\mathrm{A}),(\mathrm{B}), \text { or } \mathrm{A}_{\mathrm{a}} \mathrm{B}_{\mathrm{b}},
$$

where $D_{i j}$ is the diffusion coefficient of the element $i$ in the phase $j$ and $C_{i}$ is the concentration of the element $i$ at the position $x$. Since the initial interface of the diffusion pair has a very steep gradient of composition, the absolute values of $J_{i j}$ at the interface are large. The large values of $\left|J_{i j}\right|$ prevent the 
formation of the intermetallic compound $\mathrm{A}_{\mathrm{a}} \mathrm{B}_{\mathrm{b}}$. It is because the atoms of $\mathrm{A}$ and $\mathrm{B}$ tend to select the fastest diffusion path allowed in the system. To initiate the formation of $\mathrm{A}_{\mathrm{a}} \mathrm{B}_{\mathrm{b}}$, the values of $\left|J_{i j}\right|$ in (A) and (B) has to be reduced to a level equivalent to or smaller than the maximum value of that in $A_{a} B_{b}$ can take. Hence, the condition to form $\mathrm{A}_{\mathrm{a}} \mathrm{B}_{\mathrm{b}}$ can be described as

$$
\left|J_{i(\mathrm{~A})}\right| \leq\left|J_{i \mathrm{~A}_{\mathrm{a}} \mathrm{B}}\right| \text { and }\left|J_{i(\mathrm{~B})}\right| \leq\left|J_{i \mathrm{~A}_{\mathrm{a}} \mathrm{B}}^{*}\right| \text {. }
$$

This condition (2) is achieved after the direct interdiffusion between $\mathrm{A}$ and $\mathrm{B}$ has proceeded to reduce the gradient of the composition to a certain level. The time required to achieve the condition (2) is named the incubation time. If there is more than one intermetallic compound that is possible to form at the interface, each phase $j$ has its critical $\left|J_{i j}{ }^{*}\right|$. The phase with a higher critical $\left|J_{i j}{ }^{*}\right|$ will appear prior to those with a lower critical $\left|J_{i j}{ }^{*}\right|$.

If the diffusion pair consists of very thin films, the condition (2) to form intermetallic compounds will be rapidly achieved. In such cases, the incubation time might not be detected. On the other hand, a bulk diffusion pair in which both end members have enough thickness will need to consider another mechanism of incubation. That is the time required to remove the oxide layers and gas-adsorption layers present on the surfaces of A and B. These surface layers interfere with the diffusion across the interface. The time required to remove these surface layers depends on the thickness of the layers. Consequently, the exposure time of the surfaces to air should be managed to control the thickness of the surface layers.

\section{Experimental Procedure}

High-purity plates of $\mathrm{Cu}(99.99 \%)$ and $\mathrm{Sn}(99.999 \%)$ having thicknesses of 0.05 and $0.5 \mathrm{~mm}$, respectively, were used in the present study. The plates were cut to $5.0 \mathrm{~mm}$ square shape. The surfaces of $\mathrm{Cu}$ and $\mathrm{Sn}$ specimens were cleaned with diluted nitric acid and diluted hydrochloric acid, respectively. The exposure time to air after the chemical cleaning was properly managed. A Sn specimen was put between two $\mathrm{Cu}$ specimens to form a diffusion pair.

Then, the paired specimens were set in a vacuum furnace. Achieving the vacuum of $1.0 \times 10^{-3} \mathrm{~Pa}$, the bonding pressure of 19.6 MPa was applied perpendicular to the interface. This value of pressure is higher than the tensile strength of $\mathrm{Sn}$. Therefore, the major part of the $\mathrm{Cu} / \mathrm{Sn}$ interface will achieve intimate contact at the beginning of the heat treatment. The specimens were heated to certain temperature between 423 and $493 \mathrm{~K}$ and held at the temperature for a certain time between 900 and $3600 \mathrm{~s}$. The annealing time for some specimens was prolonged to $3.60 \times 10^{5} \mathrm{~s}$. The temperatures employed in the present study are below the lowest eutectic between $\mathrm{Cu}_{6} \mathrm{Sn}_{5}$ and $\mathrm{Sn}$ at $500 \mathrm{~K}$ in the $\mathrm{Cu}-\mathrm{Sn}$ binary system [9]. Thus, no melt will be generated at the interface. Specimens exposed to air for various times ranging from 600 to $1.73 \times 10^{6} \mathrm{~s}$ were solid-state diffusion bonded.

The interfacial microstructures of the bonded specimens were analyzed by scanning electron microscopy (SEM) and energy dispersive X-ray spectroscopy (EDS).

\section{Results and Discussion}

Solid State Reaction Behavior at $\mathbf{C u} / \mathrm{Sn}$ Interface. It took at least $600 \mathrm{~s}$ after the chemical cleaning to set the specimens in the vacuum furnace and to start evacuation. In this section, the reaction behavior between $\mathrm{Cu}$ and $\mathrm{Sn}$ whose surfaces are exposed to air for this minimum time is described.

Fig. 1 presents a cross-sectional microstructure of the interface between $\mathrm{Cu}$ and $\mathrm{Sn}$ formed after annealing at $493 \mathrm{~K}$ for $3600 \mathrm{~s}$. Fig. 1(a) is a SEM backscattered electron image of the interface. The dark area on the left-hand side is $\mathrm{Cu}$ and the bright area on the right-hand side is Sn. Between $\mathrm{Cu}$ and $\mathrm{Sn}$, a $1.9-\mu \mathrm{m}$-thick layered reaction product is observed with a moderate tone. The molar fractions of $\mathrm{Cu}$ and $\mathrm{Sn}$ in the layered reaction product are 0.56 and 0.44 , respectively, which corresponds to $\mathrm{Cu}_{6} \mathrm{Sn}_{5}$. Fig. 1(b) shows the composition profile along the line from $\mathrm{X}$ to $\mathrm{X}$ ' marked on Fig. 1(a). Sn does not diffuse into $\mathrm{Cu}$ very much, whereas $\mathrm{Cu}$ penetrates deep into $\mathrm{Sn}$. $\mathrm{Cu}$ is detected even in the $\mathrm{Sn}$ region $10 \mu \mathrm{m}$ distant from the $\mathrm{Cu}_{6} \mathrm{Sn}_{5} / \mathrm{Sn}$ interface. Fig. 2 depicts the interfacial microstructure after 

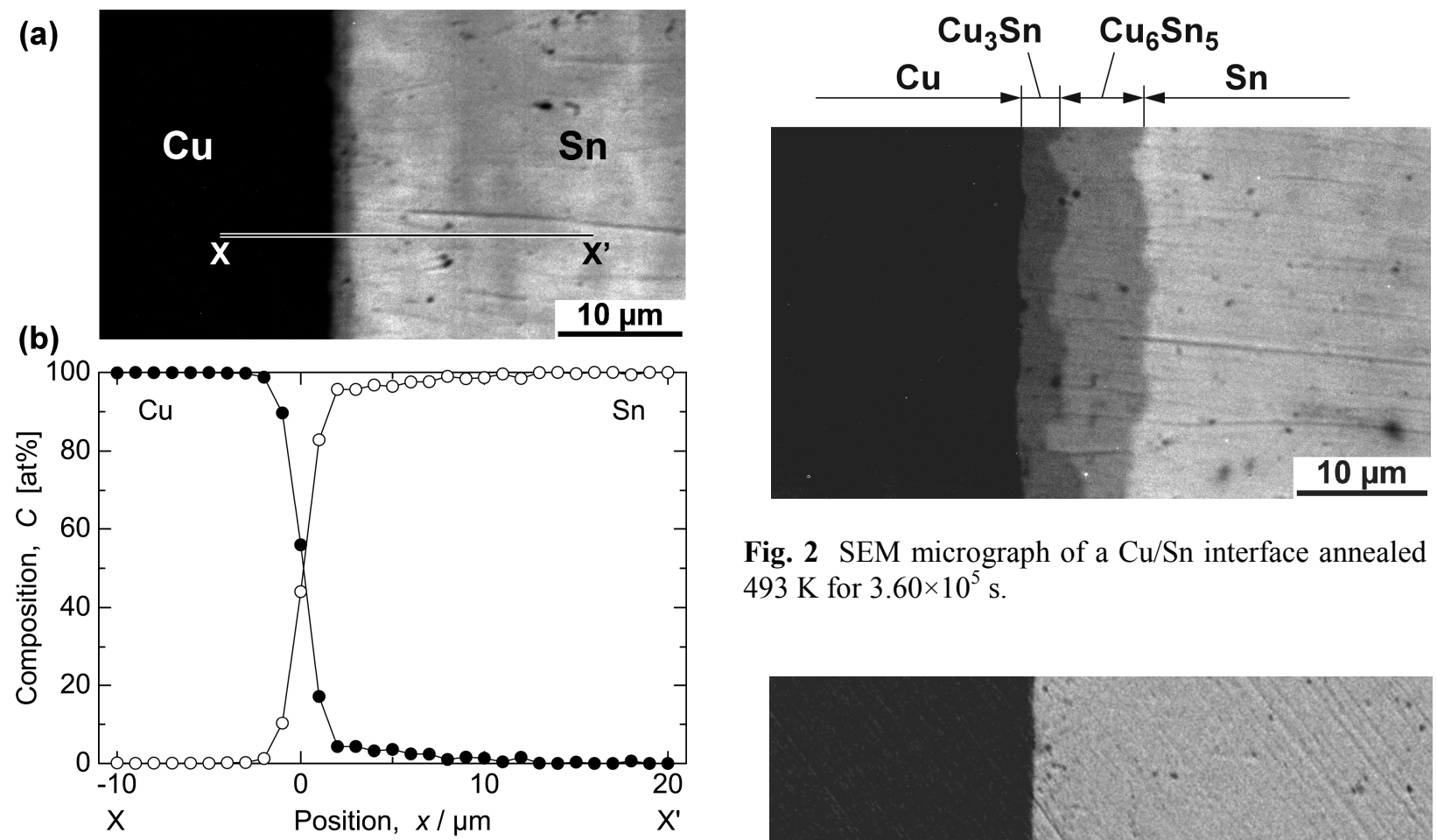

Fig. 2 SEM micrograph of a $\mathrm{Cu} / \mathrm{Sn}$ interface annealed at $493 \mathrm{~K}$ for $3.60 \times 10^{5} \mathrm{~s}$.

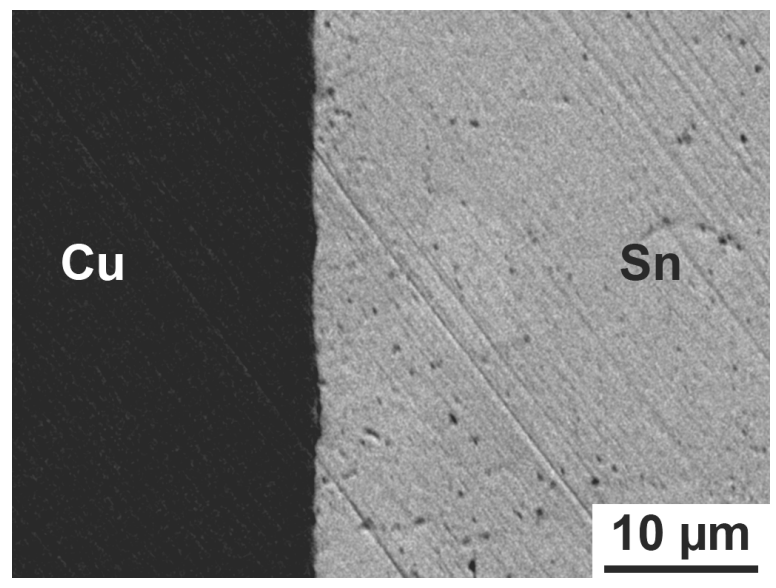

Fig. 1 Microstructure of a $\mathrm{Cu} / \mathrm{Sn}$ interface annealed at 493 $\mathrm{K}$ for 3600 s. (a) SEM micrograph, (b) composition profile along the line from $X$ to $X^{\prime}$ marked in Fig. 1(a).

annealing at $493 \mathrm{~K}$ for $3.60 \times 10^{5} \mathrm{~s}$. Two layered reaction products are observed. The composition analysis result indicates that the layer adjacent to $\mathrm{Cu}$ which appears with a darker tone than the other reaction product is $\mathrm{Cu}_{3} \mathrm{Sn}$, whereas the other layer adjacent to $\mathrm{Sn}$ is $\mathrm{Cu}_{6} \mathrm{Sn}_{5}$. The average thicknesses of the $\mathrm{Cu}_{3} \mathrm{Sn}$ and $\mathrm{Cu}_{6} \mathrm{Sn}_{5}$ layers are

Fig. 3 SEM micrograph of a $\mathrm{Cu} / \mathrm{Sn}$ interface annealed at $423 \mathrm{~K}$ for $3.60 \times 10^{5} \mathrm{~s}$. 3.3 and $6.1 \mu \mathrm{m}$, respectively. These results agree with the reports $[1,3,4,6]$ which suggest the formation of $\mathrm{Cu}_{6} \mathrm{Sn}_{5}$ precedes that of $\mathrm{Cu}_{3} \mathrm{Sn}$.

On the other hand, the interface formed by annealing at a lower temperature of $423 \mathrm{~K}$ for $3.60 \times 10^{5}$ $\mathrm{s}$ depicted in Fig. 3 retains the direct interconnection between $\mathrm{Cu}$ and $\mathrm{Sn}$. This result indicates that the annealing time of $3.60 \times 10^{5} \mathrm{~s}$ is still in the incubation process for the annealing temperature of $423 \mathrm{~K}$.

Many reports have argued that $\mathrm{Cu}_{3} \mathrm{Sn}$ and $\mathrm{Cu}_{6} \mathrm{Sn}_{5}$ are formed by annealing at lower temperatures and shorter times $[1,3,4]$. Those reports may seem inconsistent with the results in the present study. However, the difference in their experiments and the present study is found in the thicknesses of $\mathrm{Cu}$ and $\mathrm{Sn}$ specimens. All those reports have used very thin bilayer films of $\mathrm{Cu}$ and $\mathrm{Sn}$ as the diffusion pairs, whereas piled thick plates of $\mathrm{Cu}$ and $\mathrm{Sn}$ are employed in the present study. The thicker end members in the diffusion pair can result in the longer incubation time, as described above.

The thickness of the $\mathrm{Cu}_{6} \mathrm{Sn}_{5}$ layer formed by annealing at each condition of temperature and time is plotted in Fig. 4 as a function of the square-root of the annealing time. In every annealing temperature employed in the present study, distinct incubation times are seen. The incubation time becomes shorter at higher annealing temperature. An annealing time longer than the incubation time results in the formation and growth of the $\mathrm{Cu}_{6} \mathrm{Sn}_{5}$ layer. The thickness of the layer increases monotonically by extending the annealing time obeying the parabolic law. The layer grows faster at higher temperatures. The temperature dependence of the growth rate has been analyzed using an Arrhenius-type function. 


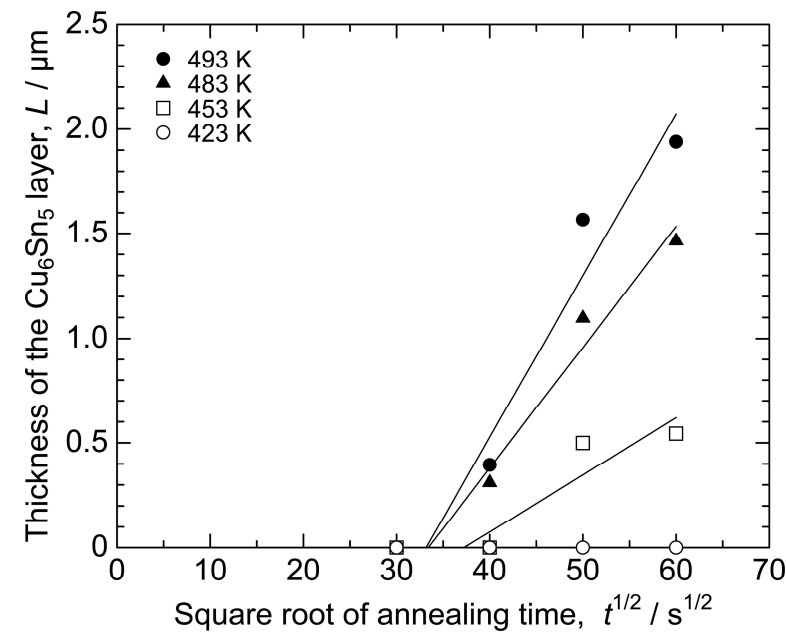

Fig. 4 Growth behavior of the $\mathrm{Cu}_{6} \mathrm{Sn}_{5}$ layer in the early stage of reaction in which $\mathrm{Cu}_{3} \mathrm{Sn}$ is not present.

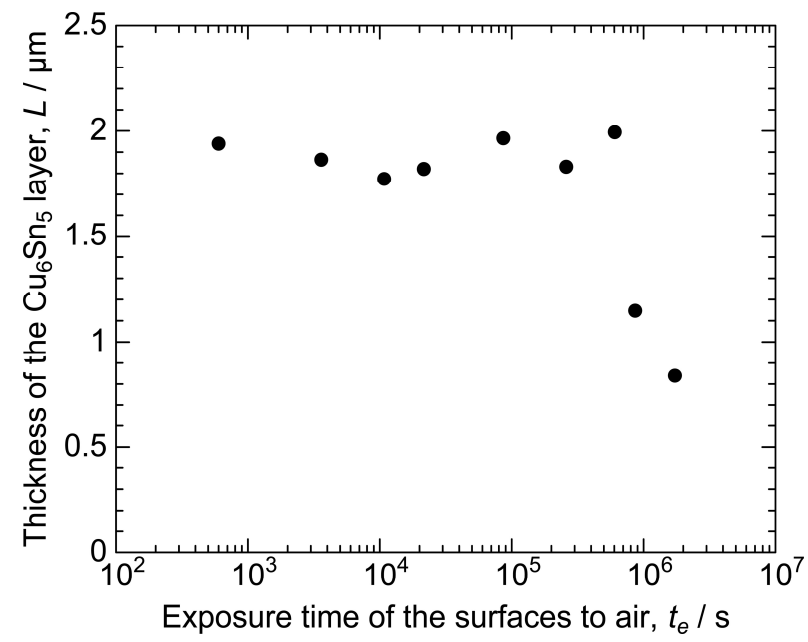

Fig. 5 Effect of the exposure time of specimens to air on the thickness of the $\mathrm{Cu}_{6} \mathrm{Sn}_{5}$ layer formed by the same annealing condition of $493 \mathrm{~K}, 3600 \mathrm{~s}$.

The frequency factor and the apparent activation energy for growth have been derived as $7.52 \times 10^{-5}$ $\mathrm{m}^{2} \mathrm{~s}^{-1}$ and $95.5 \mathrm{~kJ} \mathrm{~mol}^{-1}$, respectively.

These values are both considerably higher than those previously reported [2, 5]. It is because the values appearing on previous reports are derived from the interfaces in the presence of $\mathrm{Cu}_{3} \mathrm{Sn}$, whereas those derived in the present study are from the interfaces in which $\mathrm{Cu}_{3} \mathrm{Sn}$ is still in the incubation process. Therefore, the growth rate of the $\mathrm{Cu}_{6} \mathrm{Sn}_{5}$ layer is considerably higher in the early stage in which $\mathrm{Cu}_{3} \mathrm{Sn}$ is not formed.

Reaction of $\mathrm{Cu}$ and Sn Exposed to Air. In this section, the reaction behavior between $\mathrm{Cu}$ and Sn whose surfaces are exposed to ambient air for various times is described.

The effect of the exposure was investigated by comparing the thickness of the $\mathrm{Cu}_{6} \mathrm{Sn}_{5}$ layer formed by the same annealing condition. In this experiment, $\mathrm{Cu}$ and $\mathrm{Sn}$ specimens were exposed to air for the same time. The thickness of the $\mathrm{Cu}_{6} \mathrm{Sn}_{5}$ layer formed by the annealing at $493 \mathrm{~K}$ for $3600 \mathrm{~s}$ are plotted in Fig. 5 in relation with the exposure time. The thickness of the $\mathrm{Cu}_{6} \mathrm{Sn}_{5}$ layer appears almost equal as long as the exposure time does not exceed $6.05 \times 10^{5} \mathrm{~s}$, whereas the extended exposure significantly suppresses the growth of the $\mathrm{Cu}_{6} \mathrm{Sn}_{5}$ layer.

In addition to the growth suppression, voids start to be formed at the interface when the exposure time is $8.64 \times 10^{4} \mathrm{~s}$ or longer. Fig. 6 shows two interfaces after annealing at $493 \mathrm{~K}$ for $3600 \mathrm{~s}$ using $\mathrm{Cu}$ and $\mathrm{Sn}$ exposed for considerable long time to air. Fig. 6(a) is the interface of $\mathrm{Cu}$ and Sn exposed for $8.64 \times 10^{4} \mathrm{~s}$. This exposure time is short for suppressing the growth of the $\mathrm{Cu}_{6} \mathrm{Sn}_{5}$ layer. The $\mathrm{Cu}_{6} \mathrm{Sn}_{5}$ layer has grown to a similar
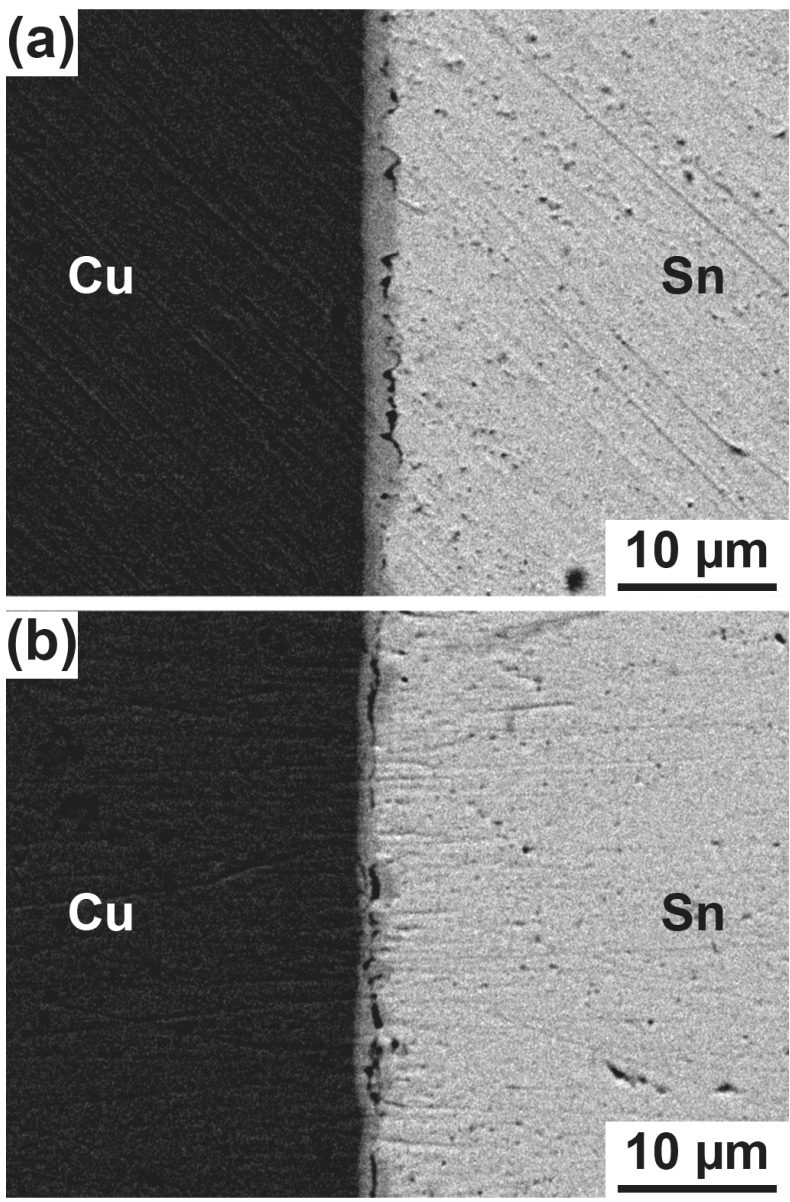

Fig. 6 SEM micrographs of $\mathrm{Cu} / \mathrm{Sn}$ interfaces annealed at $493 \mathrm{~K}$ for $3600 \mathrm{~s}$ using $\mathrm{Cu}$ and $\mathrm{Sn}$ exposed to air for long time. (a) The exposure time is $8.64 \times 10^{4} \mathrm{~s}$, (b) $8.64 \times 10^{5} \mathrm{~s}$. 
thickness of that shown in Fig. 1. However, voids are already formed between the $\mathrm{Cu}_{6} \mathrm{Sn}_{5}$ layer and $\mathrm{Sn}$. On the other hand, the interface of $\mathrm{Cu}$ and $\mathrm{Sn}$ exposed for $8.64 \times 10^{5} \mathrm{~s}$ is depicted in Fig. 6(b). The thickness of the $\mathrm{Cu}_{6} \mathrm{Sn}_{5}$ layer appears thinner than that shown in Fig. 6(a) indicating that the growth of the layer is suppressed. The voids are formed in the $\mathrm{Cu}_{6} \mathrm{Sn}_{5}$ layer as well as at the interface between the $\mathrm{Cu}_{6} \mathrm{Sn}_{5}$ layer and $\mathrm{Sn}$.

Two phenomena, the growth suppression of the $\mathrm{Cu}_{6} \mathrm{Sn}_{5}$ layer and the void formation, appeared as the effect of exposure of $\mathrm{Cu}$ and $\mathrm{Sn}$ to air. To identify which of $\mathrm{Cu}$ or $\mathrm{Sn}$ is responsible for each phenomenon, either of $\mathrm{Cu}$ or $\mathrm{Sn}$ exposed to air for a long time of $1.30 \times 10^{6} \mathrm{~s}$ were combined with the counterpart of the diffusion pair exposed for only $600 \mathrm{~s}$ and annealed at $493 \mathrm{~K}$ for $3600 \mathrm{~s}$. Fig. 7(a) depicts the interface between $\mathrm{Cu}$ exposed for $600 \mathrm{~s}$ and $\mathrm{Sn}$ for $1.30 \times 10^{6} \mathrm{~s}$. The thickness of the $\mathrm{Cu}_{6} \mathrm{Sn}_{5}$ layer is $1.9 \mu \mathrm{m}$, indicating that the growth of the layer is not suppressed. The void formation is also scarcely observed. On the other hand, both the growth suppression of the $\mathrm{Cu}_{6} \mathrm{Sn}_{5}$ layer and the formation of voids are clearly seen on the interface between $\mathrm{Cu}$ exposed for $1.30 \times 10^{6} \mathrm{~s}$ and $\mathrm{Sn}$ for 600 s, depicted in Fig. 7(b). These results indicate that the exposure of $\mathrm{Cu}$ to air dominates the two phenomena.

The affinity of materials with oxygen can be
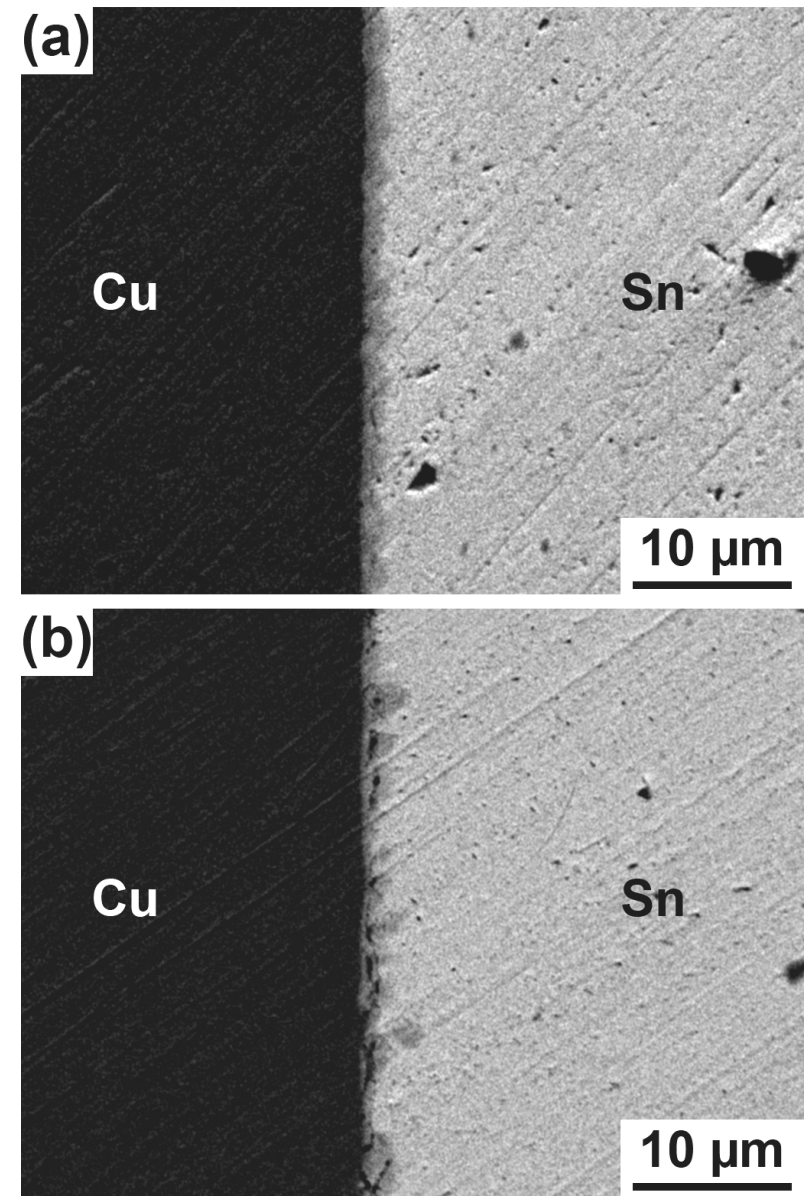

Fig. 7 SEM micrographs of $\mathrm{Cu} / \mathrm{Sn}$ interfaces annealed at $493 \mathrm{~K}$ for $3600 \mathrm{~s}$ using either of $\mathrm{Cu}$ or $\mathrm{Sn}$ exposed to air for $1.30 \times 10^{6} \mathrm{~s}$. The exposure time of the counterpart is $600 \mathrm{~s}$. (a) $\mathrm{Sn}$ is exposed for long time, (b) $8.64 \times 10^{5} \mathrm{~s}$. evaluated using the Gibbs energy of formation of the corresponding oxides, which are summarized in the Ellingham diagram. The diagram suggests that the affinity of $\mathrm{Sn}$ is higher than that of $\mathrm{Cu}$, i.e., the reduction reaction of $\mathrm{Cu}$-oxides by $\mathrm{Sn}$ can proceed spontaneously, whereas that of Sn-oxides by $\mathrm{Cu}$ hardly occurs. In addition, the $\mathrm{Cu}-\mathrm{O}$ and Sn-O binary phase diagrams [9] suggests that solubility of oxygen in both $\mathrm{Cu}$ and $\mathrm{Sn}$ are very small at the temperatures employed in the present study. These facts indicate that it is difficult for $\mathrm{Cu}$ to reduce Sn-oxides by both reaction and dissolution. Thus, the formation of Sn-oxides by the prolonged exposure to air would have a more significant effect on the interfacial behavior than $\mathrm{Cu}$-oxides would have. This prediction is contrary to the result of the present study. It needs to consider the mechanical behavior of the materials to explain the result [10]. Since $\mathrm{Sn}$ is far softer than $\mathrm{Cu}$, the bonding pressure will induce plastic deformation mostly in Sn to form intimate contact. This deformation will destroy and disperse the surface layers formed by exposure to air. Thus, fresh surface of Sn will be in contact with the counterpart of the diffusion pair. On the other hand, the deformation of $\mathrm{Cu}$ is hardly expected. The surface layers formed by the exposure will retain its structure even after the bonding force is applied. Consequently, the surface layers have to be removed by the interfacial reaction, which takes a longer time than plastic deformation.

Two mechanisms can be considered for the void formation: the Kirkendall void formation and gas generation due to the decrease of solubility during cooling down. The former mechanism, however, will have to occur also in the diffusion pairs which are not exposed to air for a long time. Under the bonding pressure, the voids tend to shrink [10]. If the presence of oxygen in the vicinity of the 
interface affects the diffusion coefficient, this mechanism may hold true. On the other hand, the latter mechanism is appropriate for materials which have absorbed gas atoms at high temperatures. In this case, the voids would be filled with $\mathrm{O}_{2}$ gas.

\section{Summary}

The early stage of interfacial reaction between $\mathrm{Cu}$ and $\mathrm{Sn}$ has been investigated by solid state diffusion bonding of high-purity plates of $\mathrm{Cu}$ and $\mathrm{Sn}$. The following knowledge has been obtained:

(1) A clear incubation time for the formation of intermetallic compounds is observed at every temperature between 423 and $493 \mathrm{~K}$.

(2) The incubation time becomes shorter at higher annealing temperature. On the other hand, the growth rate of the reaction products becomes higher at higher annealing temperatures.

(3) Annealing at $423 \mathrm{~K}$ for up to $3.60 \times 10^{5} \mathrm{~s}$ does not form any intermetallic compounds at the interface.

(4) The exposure of $\mathrm{Cu}$ surface to air affects the interfacial reaction. Voids are formed between $\mathrm{Cu}_{6} \mathrm{Sn}_{5}$ and $\mathrm{Sn}$ by the diffusion bonding at $493 \mathrm{~K}$ for $3600 \mathrm{~s}$ using the $\mathrm{Cu}$ plates exposed for $8.64 \times 10^{4} \mathrm{~s}$ or longer to air. Furthermore, the thickness of the reaction product layer formed by the same annealing at $493 \mathrm{~K}$ for $3600 \mathrm{~s}$ is reduced when the $\mathrm{Cu}$ plates exposed for $8.64 \times 10^{5} \mathrm{~s}$ or longer to air are used.

\section{Acknowledgment}

The present study has been implemented under support from the Japan Society for Promotion of Science through Grants-in-Aid for Scientific Research (No. 18206076).

\section{References}

[1] K. N. Tu: Acta Metall. Vol. 21 (1973), p. 347.

[2] M. Onishi and H. Fujibuchi: Trans. Jpn. Inst. Met. Vol. 16 (1975), p. 539.

[3] K. Fujiwara, M. Ohtani, T. Isu, S. Nango, R. Kawanaka and K. Shimizu: Thin Solid Films Vol. 70 (1980), p. 153.

[4] R. Chopra, M. Ohring and R. S. Oswald: Thin Solid Films Vol. 94 (1982), p. 279.

[5] R. A. Gagliano and M. E. Fine: J. Electron. Mater. Vol. 32 (2003), p. 1441.

[6] C. N. Liao and C. T. Wei: J. Electron. Mater. Vol. 33 (2004), p. 1137.

[7] A. Paul, A. A. Kodentsov and F. J. J. van Loo: Z. Metallkd. Vol. 95 (2004), p. 913.

[8] T. Takenaka, S. Kano, M. Kajihara, N. Kurokawa and K. Sakamoto: Mater. Sci. Eng. A Vol. 396 (2005), p. 115.

[9] Binary Alloy Phase Diagrams, second edition plus updates on CD-ROM, edited by T. B. Massalski, H. Okamoto, P. R. Subramanian, and L. Kacprzak, ASM International, Materials Park, Ohio, USA, (1996).

[10] Y. Takahashi and K. Inoue: Mater. Sci. Technol. Vol. 8 (1992), p. 953. 